\title{
CLIMATE CHANGE AND THE LIMITS OF THE POSSIBLE
}

\author{
JEDEDIAH PURDY $\dagger$
}

Climate change looks to be more than just another environmental problem. It threatens to test the limits of our dominant ways of understanding and solving, not just environmental problems, but problems of political economy generally. ${ }^{1}$ Climate change has distinctive temporal and spatial features - how long it takes to unfold and the ways in which its effects are distributed across the globe - which may outstrip the capacity of our basic principles of economic and political decision-making. If so, then understanding the issue in a static way may ensure that we expect to fail in addressing it and are inarticulate about our prospects for success. That is, if we assume that economic and political decisions reflect the present distribution of self-interest within the existing structure of rules and institutions, we may be unable to see our way beyond the problem, because it so neatly frustrates the problem-solving power of our current arrangements. We may need, instead, to adopt a dynamic view of political economy.

$\dagger$ Associate Professor of Law, Duke University Law School. J.D., Yale Law School, A.B., Harvard College. I thank Jonathan Wiener, my co-teacher in a course on Climate Change and the Law, and students in that class for helpful and insightful conversation about this issue.

1. "Political economy" is an important term here. I use it to refer to economic activity, not as a domain of independent, quasi-natural principles (for instance, decisions based on microeconomic rationality aggregating predictably into institutional arrangements which advance the interests of the participants), but as a domain that interacts dynamically with political institutions and decisions. In my sense of political economy, while economic activity has a logic and power of its own, it is also a creature of political decisions such as the definition and assignment of property rights and the terms of regulation. This meaning is different from some contemporary uses, which treat it as a catchword for public-choice analysis of political decisions, in effect reducing politics to an extension of microeconomic rationality. It would have been familiar to nineteenth- and early twentieth-century students of economics and political institutions. See, e.g., Robert L. HAle, Freedom Through Law: Public Control Of PrIVATE GOVERNING POWER 3-44, 385-99 (1952) (diagnosing private economic rights as creatures of public law and enforcement); John StUART Mill, PRINCIPLES OF POLITICAL ECONOMY 209-44 (1994) (exploring government's definition of economic rights as an instrument of production and distribution), 727-33 (on the role of state in economic life, generally) (Prometheus Books 2004) (1848). 
A dynamic view of political economy has certain core features. First, it assumes that the interests that actors pursue in politics are sometimes endogenous to politics itself. That is, politics is not only a vehicle for pursuit of interests that pre-exist and stand apart from political contest. Sometimes it is also the source of new understandings of the relevant interests of the actors involved. The deliberation, struggle, and problem-solving of politics can change how those who participate understand and experience their own motives. ${ }^{2}$ Second, a dynamic view assumes that interests also may be endogenous to economic activity. That is, the characteristic decisions and transactions of economic life may influence how participants understand their own motives in that activity. ${ }^{3}$ In a dynamic view, then, economic and political life has a double character. On the one hand, it centrally involves what static analysis concentrates on: pursuit of existing interests through existing rules and institutions. On the other hand, however, it also involves the dynamic activity of reexamining, newly discovering, or otherwise changing the relevant interests.

Third, a dynamic view assumes a feedback relationship between understandings of interests and institutional design. Thus a feature of political economy in a dynamic view is that actors try to institute arrangements that reinforce their current view of relevant interests, and the arrangements that arise, in turn, shape the motives of the future. The politics of institutional design, then, is not only about what we can get; it is also about what we value, and about the institutional context in which we will reach our next set of judgments about what we value.

What I am calling a dynamic analysis is not the same as "taking values seriously" as distinct from "crasser" interests or inarticulate preferences. ${ }^{4}$ A static analysis can perfectly well acknowledge that

2. See Amartya SEn, Goals, Commitment, and Identity, in RATIONALITY AND FREEDOM 206, 206-24 (2002) (on deliberation and reflection as essential to an adequate view even of economic decision-making); AMARTYA SEN, Environmental Evaluation and Social Choice, in RATIONALITY AND FREEDOM, supra, at 531, 531-52.

3. See Amartya Sen, Development As Freedom 197 (1999) (on the power of participation in labor markets to increase some women's sense of agency and autonomy); Yochai Benkler, Sharing Nicely: On Shareable Goods and the Emergence of Sharing as a Modality of Economic Production, 114 YALE L.J. 273, 328 (2004) (on the power of a new mode of production to increase the effective power of motives such as "love, status, and esteem").

4. For the thought of two legal theorists who have focused on the alleged tendency of a microeconomic account of choice to collapse into subjectivism and instrumentalism, blind to qualitative distinctions in value, see GREGORY ALEXANDER, COMMODITY AND PROPRIETY: Competing Visions OF Property In AMERICAN Legal ThOught 1776-1970 1-4 (1997) 
actors' self-interest includes their values, however they understand those: motives need not be restricted to wealth or some other "objective advantage," nor must actors experience themselves as "maximizing utility" or "maximizing preference-satisfaction," rather than pursuing values qua values. A dynamic analysis is distinctive, however, in that it must take values seriously in a somewhat different way from a static approach. In a dynamic analysis, values interact as efforts at interpersonal persuasion and subjective insight: they qualitatively influence the set of interests (including values - again, I am not setting the terms in opposition to each other) that operates in the next iteration of decision-making. Understanding this activity may require an interpretive effort, an attempt to grasp the ways in which persuasion occurs.

\section{Climate Change And Modern Political ECONOMY}

The temporal and spatial scales of climate change might have been designed to confound the basic operating principles of modern political economy. Take the first principle of economic life: the idea, made cliché in Adam Smith's metaphor of the invisible hand, that when individuals pursue their respective self-interest, their choices will aggregate to maximize social welfare. ${ }^{6}$ This idea depends, of course, on the premise that people take on - internalize, in the preferred language - the benefits and harms that flow from their decisions. Otherwise, externalities kick in: benefits and harms that do not redound to those who create them. ${ }^{7}$ These may lead people to do too few beneficial things, because they do not themselves get the full benefit, or - what is salient here - too many harmful things, because they need not absorb the full harm. This premise of economic life, commonsensical though it can seem, is a defining principle of modern

(connecting the negative liberty secured by market property with an economically inflected subjectivism of value); MARGaret Jane RAdin, CONTESTED Commodities: The Trouble With Trade In SEX, Children, Body Parts, AND Other Things 79-102 (arguing that a market logic of choice and valuation flattens qualitative moral distinctions and leads choosers to view all things as instruments to satisfy their subjective preferences).

5. For a rigorous account of the distinctive commitments of a mode of social inquiry committed to interpretation, see CHARLES TAYLOR, What Is Human Agency?, in HUMAN Agency And Language 15, 15-44 (1985); Charles TAYlor, Self-Interpreting Animals, in HuMAN AGENCY AND LANGUAGE, supra, at 45, 45-76.

6. For the origins and ambiguities of this metaphor, see EMMA ROTHSCHILD, ECONOMIC SENTIMENTS: ADAM SMITH, CONDORCET, AND THE ENLIGHTENMENT 116-56 (2001).

7. See Robert C. Ellickson, Property in Land, 102 YALE L.J. 1315, 1322-35 (1993) (discussing the concept of externalities and legal responses thereto). 
civilization and quite distinct from the way earlier societies understood economic order. ${ }^{8}$

Climate change threatens to be, fairly literally, the externality that ate the world. Within a year of emission, carbon dioxide is uniformly distributed throughout the global atmosphere. Someone who uses energy derived from fossil fuels gets the full benefit of that power while evenly dividing the atmospheric harm with - at the time of writing - somewhat more than 6.6 billion people. ${ }^{9}$ That is a ratio of benefit to harm guaranteed to create overindulgence. (Imagine being able to enjoy a certain elevation, giddiness, and self-confidence with every drink you took, while distributing hangovers, weight gain, chemical dependence, and impaired driving across the entire human population. For a while we'd all be pretty giddy, excepting the Mormons, and distilleries would do a booming business; but eventually everybody else's drinking would leave each of us desperately dissolute.) When the aggregate result of externalitydriven overuse is potentially catastrophic climate change, the principle of maximizing social welfare through individual maximizing decisions has hit a tragic juncture, in which externalized harms overwhelm internalized benefits.

The invisible hand premise of economic life has a complementary political premise: when individual pursuit of selfinterest runs off the rails, political decisions to rearrange property rights or otherwise regulate activity can correct the problem. ${ }^{10}$ The paradigm cases of such political intervention are barring selfinterested activity that offends core moral sensibilities, such as inducing others to enter contracts of enslavement or for the sale of their organs, and correcting externalities. ${ }^{11}$ Correcting greenhouse gas externalities is not, technically speaking, all that difficult. Either a tax on emissions of carbon dioxide and its heat-forcing equivalents or

8. For an illuminating discussion of the distinctness of this idea as an early-modern innovation in the self-understanding of society, see CHARLES TAYLOR, A SECULAR AGE 159-85 (2007).

9. According to the United Nations' 2006 estimate, global population was a bit over 6.5 billion in 2005 and is estimated to reach just over 6.9 billion in 2010. See United Nations Economic and Social Development, http://esa.un.org/unpp/p2k0data.asp (last visited Feb. 13, 2008).

10. See Ellickson, supra note 7 (discussing property regimes as instruments for managing externalities); Jedediah Purdy, People as Resources: Recruitment and Reciprocity in the Freedom-Promoting Approach to Property, 56 DUKE L.J. 1047, 1085-89 (2007) (discussing the prohibition on enslavement as a premise of the modern property regime).

11. See Ellickson, supra note 7; see also Purdy, supra note 10. 
a cap-and-trade system could impose on emitters a monetary expression of the otherwise externalized costs of their emissions. ${ }^{12}$ This would reduce short-run demand and, more importantly, spur investment in alternative energy sources and more efficient patterns of energy use. ${ }^{13}$

The difficulty is that political and legal decisions have their own scales of space and time, which are not those of climate change. Spatially, most effective political decisions occur at the scale of the nation-state and its jurisdictional subdivisions. A truly global problem reproduces for a nation the same problem of externalities as for individuals: a national public must absorb the full cost of any measure it adopts to address climate change, but will receive only a fraction of the globally distributed benefit - a benefit, moreover, that may be overwhelmed by others' growing emissions. ${ }^{14}$ From the point of view of a politician proposing measures to address climate change, the proposal can resemble a massive foreign-aid project. A United States policy to reduce greenhouse gas emissions, for instance, would distribute 95 percent of its benefit to foreigners on a per capita basis. ${ }^{15}$ National-level action is likely to be both politically unattractive and environmentally ineffective for these reasons. The scale of a political fix will have to be that of the problem: all the earth.

The problem is even worse on the global scale of coordinated international action. The anticipated effects of climate change, while highly uncertain, are quite diverse. Thus on some prominent estimates, the United States would have been a massive net loser from adopting the Kyoto Protocol, even with total global compliance, because the costs of implementation would have been much greater than the cost from unmitigated climate change. ${ }^{16}$ Some other countries, notably Russia, might be net gainers from climate change, at least in the medium term, even without considering the costs of

12. For a sketch of the respective mechanisms and their advantages and disadvantages, see William Chameides \& Michael Oppenheimer, Carbon Trading over Taxes, 315 SCIENCE 1670 (2007).

13. For an argument that such a policy would ultimately prove cost-effective, see RICHARD A. POSNER, CATASTROPHE: RiSK AND RESPONSE 155-65 (2004).

14. See Jonathan B. Wiener, Think Globally, Act Globally: The Limits of Local Climate Policies, 155 U. PENN L. REV. 1961, 1966-73 (2007) (setting out the functional disadvantages of any sub-global effort to control climate change).

15. I base this on the United States' share, 300 million, of the world population, approximately six billion.

16. See Cass R. Sunstein, Worst-CASE Scenarios 71-117 (2007). 
mitigation. ${ }^{17}$ As Jonathan Wiener has pointed out, because the decision rule for international treaties is consensus - that is, each country's consent is necessary to create a comprehensive regulatory scheme - such diverse interests present a serious impediment to creating an effective international regime. ${ }^{18}$ One might think that it should be possible in principle to redistribute the benefits of climatechange mitigation by buying off reluctant countries, as Europe did for Russia in inducing it to join Kyoto. ${ }^{19}$ This approach, though, presents serious difficulties: strategic misrepresentation of anticipated national interest, as countries jockey to be bought off; pure holdout problems, even without such misrepresentation; disputes about acceptable distributions of benefits and burdens, including politicized arguments about international distributive justice; and, closely linked to the last, domestic political reluctance to subsidize the mitigation efforts of foreigners. $^{20}$

Even more basic, however, is the problem of temporal scale. Each year's greenhouse gas emissions commit the global atmosphere to decades of resulting change, and the sum of atmospheric changes, arising from interacting natural and anthropogenic influences, may emerge over an even longer time. ${ }^{21}$ This means that the benefits of mitigating climate change will accrue to future generations while the living bear the costs. Domestic political decision-making, particularly in democracies, is tied to electoral cycles ranging ordinarily from two years (the United States House of Representatives) to seven (the maximum period between United Kingdom parliamentary elections). Within any political cycle, it is highly likely that the costs of a serious

17. See Jonathan B. Wiener, Designing Global Climate Regulation, in Climate CHANGE POLICY: A SuRVEY 151, 160 (Stephen Schneider, Armin Rosencranz \& John O. Niles eds., Island Press 2002).

18. See id. at 161-62, 166-67.

19. See id. at 169.

20. On competing approaches to international distributive justice in connection with climate change, see Peter Singer, One World: The Ethics Of Globalization 14-51 (2002); Stephen M. Gardiner, Ethics and Global Climate Change, 114 ETHICS 555 (2004). On the relevance of ideas of fairness to the American political debate over the Kyoto Protocol, see Frank Luntz, The Environment: A Cleaner, Safer, Healthier America 137 (2002) (strategy memo to the White House for Republican Party candidates), available at http://www2.bc.edu/ plater/Newpublicsite06/suppmats/02.6.pdf ("The 'international fairness' issue is the emotional home run.").

21. For a survey of the range of potential impacts, see INTERGOVERNMENTAL PANEL ON Climate Change, Summary for Policymakers, in Climate Change 2007: THE Physical SCIENCE BAsis. CONTRIBUtion of WORKING Group I tO THE FourTh ASSESSMENT REPORT OF THE INTERgovernmental PANEL on Climate CHANGE (S. Solomon et al. eds., 2007). 
mitigation effort will outweigh the benefits. Moreover, the benefits are unavoidably uncertain because so many elusive and perhaps unanswerable questions attach to climate forecasting. ${ }^{22}$ Indeed, the benefits are never knowable, because they are calculated in harms that did not occur, relative to unavoidably speculative alternative scenarios. A politician seeking constituent support for climatechange policy must make the case for present sacrifices in the interest of future generations. Those beneficiaries are strangers to the present generation that bears the cost - the future, like the past, is a foreign country - and their benefits are unavoidably matters of guesswork, both now and in the future.

It might seem, then, that climate change is the Achilles heel of modern political economy, a problem whose spatial and temporal scale produces overwhelming externalities and confounds political efforts to address them. Literature concentrating on the difficulties I have set out so far has suggested as much, though in less dramatic terms. ${ }^{23}$ More popular commentators have described the issue as one that calls into question the basic premises of our political and economic life. ${ }^{24}$

\section{Climate Change And Political Psychology}

So, a way of understanding economic and political decisions that envisages people as rational in a microeconomic way - that is, as maximizing their own self-interest - provides a set-piece of pessimism. Of course, it is conceivable that people could be motivated to address climate change if they were highly altruistic in their motives, taking in both living foreigners and future generations;

22. See id. For treatments of some of the disastrous scenarios associated with climate change, see Posner, supra note 13, at 43-58; Peter Schwartz and Doug Randall, An Abrupt Climate Change Scenario and Its Implications for United States National Security (2003) (unpublished paper commissioned by United States Department of Defense, on file with author).

23. See, e.g., Wiener, supra note 14; SUNSTEIN, supra note 16, at 101-04. Recognizing the difficulty presented by climate change under a static analysis, Sunstein has expressed increasing interest in the role of moral considerations and dynamic analysis. See Cass R. Sunstein, The Complex Climate Change Incentives of China and the United States 30-35 (2007) (unpublished paper, on file with author).

24. See Anatol Lieven, The End of the West as We Know It?, InTERnATIONAL HeRALD Tribune, Dec. 28, 2006; Albert Gore, Nobel Prize Lecture in Stockholm, Sweden (Dec. 10, 2007) ("Indeed, without realizing it, we have begun to wage war on the earth itself. Now, we and the earth's climate are locked in a relationship familiar to war planners: 'Mutually assured destruction."'). 
but, generally speaking, they are not. ${ }^{25}$ If anything, conventional rates of discounting for the value of future lives probably overstate the willingness of the living to make concrete sacrifices now for the wellbeing of future generations. ${ }^{26}$ Conventional rational behavior by individuals with representative values looks like a recipe for shared disaster.

A similarly pessimistic picture emerges if we begin from a different and complementary account of decision-making: the psychological portrait of individuals' persistent and patterned deviation from microeconomic rationality. Ranged together under labels such as "cognitive bias" and "behavioral economics," these deviations comprise ways in which individuals differentially assess alternatives that, viewed according to some canon of rationality, are not relevantly different. For instance, in assessing the importance of a matter - say, the magnitude of risk associated with it or the urgency of doing something about it - people overestimate greatly the importance of phenomena that are salient, that is, readily available to the mind. ${ }^{27}$ Salience is a cultural fact, often occasioned by a highly visible event. For instance, terrorism acquired great salience as a threat in the wake of September 11, 2001, with the result that Americans not only ranked it very high among threats and problems facing the country, but estimated their personal risk of suffering a terrorist incident at a little over eight percent - a vast overstatement, which would have more than 25 million Americans a year directly affected by terrorism. ${ }^{28}$ Historically, environmental legislation has often been prompted by salience-producing incidents, such as the burning of the Cuyahoga River, which contributed to the Clean Water Act, and the discovery of toxins at Love Canal, which inspired Superfund (CERCLA) legislation. ${ }^{29}$ So far, such salience-producing events have been elusive for climate change, perhaps because the relevant causal links are subtle and open to dispute. Hurricane Katrina was horrific - enough so to make salient the impression that the Bush Administration was incompetent and callously indifferent to

25. See SUNSTEIN, supra note 16 , at 109-11.

26. On the moral considerations attending discounting, see id. at 244-74; Daniel Farber, From Here to Eternity: Environmental Law and Future Generations, 2003 U. ILL. L. REV. 289 (2003); Frank Ackerman \& Lisa Heinzerling, Pricing the Priceless, 150 U. PENN L. REV. 1553 (2002).

27. See SUNSTEIN, supra note 16 , at 54-60.

28. See id. at 43 .

29. See id. at 54-63. 
governance - but linking it to the IPCC's general forecast of more severe storms would have seemed like special pleading. ${ }^{30}$ The same goes for droughts and hot summers: is any particular season evidence of the general phenomenon of climate change? Purely speculative images, such as the immersion of many coastal areas that many saw in computer simulation in An Inconvenient Truth, seem to be received as science fiction, or guesswork, not salient fact. ${ }^{31}$ It may be that the mind's appetite for salience demands specificity and causal definiteness of a kind that a global and causally complex set of changes does not provide. If so, that would be a considerable barrier to getting political traction for the issue.

Consider another cognitive bias: people greatly value, and seek to help or avenge, individual victims of wrongs. ${ }^{32}$ As the number of victims multiplies, the value observers place on each one falls. ${ }^{33}$ Asked to contribute to a humanitarian cause, respondents give much more to help one victim whose face they are shown than in response to a description of the general problem - say, a drought or political oppression - that produces such victims. ${ }^{34}$ In fact, when shown the victim's face and given the general description, they give less than when confronted with the face alone. ${ }^{35}$ Knowledge plus sympathy is less motivationally powerful than sympathy uneducated. ${ }^{36}$ This is an especially precise rendition of Stalin's grim quip that while one death is a tragedy, a million deaths are a statistic. ${ }^{37}$ Global climate change may be, in Stalin's sense, the ultimate statistic: too diffuse and encompassing to concentrate moral attention in the way an individual face can do. ${ }^{38}$

Recent developments in public opinion around climate change are consistent with this pattern. A growing share of poll respondents

30. See id. at 59-60.

31. An InCONVENIENT Truth (Lawrence Bender Productions 2006).

32. See Paul Slovic, If I Look at the Mass, I Will Never Act: Psychic Numbing and Genocide (unpublished paper, on file with author) (2006).

33. See id.

34. See id.

35. See id.

36. See id.

37. While frequently attributed to Stalin, this grim remark is not reliably traceable to him. See Wikiquote, http://en.wikiquote.org/wiki/Joseph_Stalin\#_note-statistics (last visited February 7, 2008).

38. A distinct but related phenomenon is the extra importance which people frequently assign to problems identified with concrete and easily envisioned villains, such as Osama bin Laden. See SunsteIn, supra note 16, at 65 (on the "Goldstein effect"). 
affirms that climate change is a real, human-caused problem and that something should be done to address it. ${ }^{39}$ When, however, respondents are invited in an open-ended fashion to name the most important challenges facing the country or the issues most important to them, or when they are asked to rank a list of issues in importance, climate change makes a weak showing. ${ }^{40}$ This is consistent with the profile of an issue that has developed a good deal of credibility, but not a lot of salience. An issue with this profile may not develop the kind of committed constituency that will reward politicians for pursuing it.

\section{ANOMALIES OF CONVICTION}

The appeal of the microeconomic account of rationality is its supposed psychological realism: those who hold it are meant to be free of illusion about what motivates people. ${ }^{41}$ The microeconomic perspective has the weight of former Treasury Secretary and Harvard University president Lawrence Summers's much-invoked dictum that no one in human history has ever washed a rented car, that is, that people do not behave irrationally, even when it might be nice of them to do so. ${ }^{42}$ A similar appeal attaches to accounts of cognitive bias: this, and not some more ideally moral or rational model, describes the messed-up human predicament.

The problem is that neither model can account for some of the most important events in the history of value and decision-making,

39. See Thomas L. Brewer, Public Opinion on Climate Change Issues in the G8+5 Countries,

http://www.usclimatechange.com/downloads/PO\%2520update\%2520March\%252015\%2520200

7.doc (reporting movement in the share of respondents identifying climate change as a "very serious problem" from just over $30 \%$ to just under $50 \%$ between 2003 and 2006). In 2006, $41 \%$ of U.S. respondents said they believed climate change was caused by human activity. See New Release, Pew Center of People and the Press, Little Consensus on Global Warming (July 12, 2006), available at http://people-press.org/reports/ display.php3?ReportID $=280$. In January, 2008, a CNN/Opinion Research Corporation poll found 78\% U.S. respondents claiming global warming would be "extremely," "very," or "moderately" important in their choice of candidates. See http://www.pollingreport.com/ prioriti.htm (last visited February 7, 2008).

40. Global warming did not show up in responses to an open-ended poll conducted by CBS News in January, 2008, while only $6 \%$ of respondents to an NBC News/Wall Street Journal poll in the same period chose "environment/global warming" as the most important of a list of issues. Poll summaries available at http://www.pollingreport.com/prioriti.htm (last visited February 7, 2008)

41. See Dan. M. Kahan, The Logic of Reciprocity: Trust, Collective Action, and the Law, 102 MiCH L. REV. 71, 102 (2003) (making this observation).

42. See http://www.brainyquote.com/quotes/authors///lawrence_summers.html (last visited February 13, 2008). 
including events particularly relevant to the politics of climate change. For instance, the 1838 act of Parliament that abolished slavery throughout the British Empire has confounded generations of scholarly attempts to explain it as an expression of economic selfinterest, whether of the Empire in relation to competitors or of interest groups within the Empire. ${ }^{43}$ David Brion Davis, the foremost living scholar of slavery, has concluded that British abolition amounted to self-administered "econocide," a devastating blow to the imperial economy, and that Britons well understood this. ${ }^{44}$ To take another example, while the microeconomic theory of rationality predicts that public officials will always seek to maximize the resources and power of their branch of government, a recent, comprehensive study of United States executive branch practice shows that this is not so: for many decades, presidents and their representatives did not assert certain technically colorable claims of constitutional prerogative against the legislative branch. ${ }^{45}$ They were certainly capable of imagining and making those arguments; but they did not.

Switching from microeconomic rationality to cognitive-bias theories of political psychology, we once again find critical and relevant events that confound the conventional account. Here the problem is one of question-begging. What determines the meaning of a salient event? Take the burning of the Cuyahoga. The conflagration that preceded the Clean Water Act was not the first time the river had burned, but earlier events had not inspired a perception of environmental crisis. ${ }^{46}$ Moreover, viewed as if by an anthropologist from another culture, it is not self-evident that a burning river is a symptom of environmental crisis, rather than an entertaining side-benefit of an industrial economy - like Teflon and the space program, but more fun to watch. For this to be the meaning of the burning river, a whole series of earlier exercises in persuasion had to occur, including John Muir's Romantic evocation of an unspoiled American nature as a redemptive counterpoint to industrial

43. See DAVID BRION DAVIS, Explanations of British Abolitionism, in INHUMAN BONDAGE: THE RISE AND FALL OF SLAVERY IN THE NEW WORLD 231, 231-49 (2006).

44. See id.

45. See David Barron \& Martin S. Lederman, The Commander in Chief Power at the Lowest Ebb - A Constitutional History, 121 HARV. L. REV. 941, 952 (2008) (so stating, noting that the historical fact contradicts much commonplace supposition).

46. See Ted Nordhaus \& Michael Shellenberger, Break Through: From the DEATH OF ENVIRONMENTALISM TO THE POLITICS OF POSSIBILITY 22-24 (2007). 
society and Rachel Carson's image of a world poisoned by human misjudgment. ${ }^{47}$ These drew in turn on long traditions of moral rhetoric and imagery, notably literary Romanticism for Muir and the apocalyptic tradition for Carson. ${ }^{48}$ There is no such thing as a natural neurological fact called salience, which leads the brain to fire signals of moral distress upon certain highly visible events; rather, the moral valence of salient events, and perhaps even their salience itself, is a cultural fact formed by traditions of argument. ${ }^{49}$ This is true even in some measure of such deep patterns as the moral-psychological importance of individuals and their faces. We learn, assuredly, to regard the faces and lives of those different from us as signifying less human value than those like our own, or we learn to regard them as equally important. ${ }^{50}$

Of course, one might say that the complaint against the microeconomic-rationality approach is that it also begs the question. As noted in the Introduction, the kinds of motives that led Parliament to abolish slavery and American presidents to refrain from indefinite claims of executive power can be perfectly well modeled as "selfinterest": the formal microeconomic model of rationality implies no substantive view of what people can be expected to value. Here, however, the model is no use in making sense of policy decisions unless it involves some substantive premises. Even as basic a concept as externalities depends on what counts as a harm and what a benefit, that is, what the relevant actor values. Someone with perfectly altruistic preferences would not regard a selfless decision to give up fossil fuels as producing a positive externality; instead, he would understand himself as receiving the full benefit of the choice by the very act of benefiting others. An externality is not a natural fact, unless people's preferences are natural facts. The earlier, very standard analysis of externalities' role in climate-change politics smuggled in the reasonable premise that people's motives

47. See Rachel Carson, Silent SPring (1962); John Muir, My First Summer In the SIERRA (1911).

48. On the Romantic roots of John Muir's work, see RODERICK NASH, WILDERNESS AND THE AMERICAN MIND 122-40 (2001). On Carson's debt to the apocalyptic tradition in literature and rhetoric, see M. Jimmie Killingsworth \& Jacqueline S. Palmer, Millennial Ecology: The Apocalyptic Narrative from Silent Spring to Global Warming, in GREEN CULTURE: ENVIRONMENTAL RHETORIC IN CONTEMPORARY AMERICA 21, 21-45 (Carl G. Herndl \& Stuart C. Brown eds.,1996).

49. I discuss this point in greater detail in Jedediah Purdy, The Promise (and Limits) of Neuroeconomics, 58 ALA. L. REV. 1, 21-40 (2006).

50. See SINGER, supra note 20 , at 150-60. 
prominently, if not exhaustively, comprise their economic selfinterest. The lesson of the historical counter-examples is that this is not always the whole story, and that the rest of the story - the additional motives that drive superficially counter-intuitive decisions, or fill in the cultural meanings of salience - are historically and culturally particular. They change. To understand past decisions and the prospects of future ones, therefore, it is important to understand these motives and to begin to appreciate how they change.

\section{MORAL MOTIVES}

Let's engage values qualitatively, not as the homogenous "warm glow" that theorists sometimes add in to their utility calculus to account for anomalies, but as distinctive motives that may operate differently in different contexts. ${ }^{51}$ At least three related but distinct clusters of motive operate here - and there are certainly others, such as sympathy, which I won't take up right now. One is righteousness, the desire to be on the side of justice. ${ }^{52}$ This works on the level of identity, and is expressed through such declarations as "I am not a racist," "I wouldn't work for Blackwater," or "I don't perform abortions." Such considerations figure all the time in choices of career, political contributions (it is impossible to explain hundreds of thousands of small-denomination contributions in simple publicchoice terms, as individual attempts to purchase desired policy outcomes), participation in charity and civic life, and so forth. One of David Brion Davis's conclusions about British abolitionism is simply that millions of Britons had come to believe slavery profoundly wrong, and they wanted no part of it. ${ }^{53}$ That changed the balance of their preferences, because the desire to be right, when the alternative is a cataclysmic wrong, can overwhelm material self-interest. Indeed, it is probably time to drop the concession to microeconomic language and follow the economics Nobel Laureate Amartya Sen in insisting that calling every motive to choice a "preference" is a little too flat and generic: preferences, values, and commitments are distinct, though closely related, drivers of choice. ${ }^{54}$

51. For an example of the tendency to lump such motives into a residual category, see Kirsten Engel \& Barak Y. Orbach, Micro-Motives for State and Local Climate Change Initiatives, 2 HARV. L. \& POL'Y REV. 119 (2008).

52. For a discussion of moral identity as a motivational factor, see JONATHAN GLOVER, Humanity: A Moral History OF THE TwENTIETH CENTURY 26-30 (2001).

53. See DAVIS, supra note 43 , at 245-47.

54. See SEN, supra note 2, at 206-24. 
A second moral motive is protecting dignity, the qualities, generally close to the core of one's identity, that command respect. Not surprisingly, experimental economics shows that people will give up considerable cash rewards to punish others who have tried to "short" them or otherwise failed to show them respect. ${ }^{55}$ Note that these findings are in the heartland of conventional economic selfinterest, spot transactions in which the alternative choices are defined purely in monetary amounts, though in some cases accepting the larger amount involves also accepting a measure of disrespect.

Davis's interpretation of British abolitionism places dignity near the heart of the relevant motives. He argues that a new register of personal dignity among the working and middle classes of Britain, the ideal of "free labor," drove an abhorrence of slavery. ${ }^{56}$ The free-labor ideal held that a laborer, craftsman, or smallholder who chose his own employment - in modern terms, either a labor-market participant or a yeoman - had a special dignity arising from self-ownership and autonomy. ${ }^{57}$ What made free labor "free" was always defined in part by the counterpoint of slavery. ${ }^{58}$ In Davis's view, new social classes in Britain drove the Empire to "econocide" because the imperial slave economy was anathema to their identities and sense of dignity. To return briefly to my other historical example, presidential power and the self-restraint of many executives: historian Gordon Wood concludes that a vision of "republican" dignity, in which an honorable man sought power not for its own sake but for the public good, was the source of early precedents for executive restraint. ${ }^{59}$ Executives did not behave as certain conventional models of rationality predict, not because it would not have occurred to them to do so, but because grabbing the maximum of power would have been a break with their own identities and a self-inflicted insult.

A third relevant moral motive is reciprocity. When people decide whether to participate in or defect from a scheme of cooperation, either in a small-numbers game or in a society-wide

55. See Purdy, supra note 49 , at 10-13.

56. See DAVIS, supra note 43, at 246-49.

57. See Eric Foner, Free Soil, Free labor, Free Men: The ideology of the REPUBLICAN PARTY BEFORE THE CIVIL WAR 1-37 (1970) (describing the premises and social vision of free-labor thought).

58. See id. at 11-13 (describing the basic tenets of free-labor thought and its defining contrast with the slave system of the antebellum South).

59. See Gordon S. Wood, The Radicalism of the American Revolution 205-06 (1992) (on the idea of civic honor as a motive in George Washington's decisions in the early Republic). 
practice such as voting or paying taxes, they are much more likely to cooperate if they believe others are doing so as well. ${ }^{60}$ Studies suggest that for most people, reciprocal cooperation is a basic form of satisfaction, connected with positive social reinforcement and interpersonal recognition. ${ }^{61}$ Those who try to cooperate and meet with defection in others, by contrast, feel slighted, and like suckers, and they hurry to defect themselves. ${ }^{62}$ The ideal of free labor was also an ideal of reciprocity, a vision of social order as governed by the voluntary agreements and reciprocal negotiation of autonomous yet interdependent individuals. ${ }^{63}$

\section{Climate Change, Atmospheric And Political}

With all this in mind, we can return to climate change with sharper vision. What follows from what I've set out here? First, we should understand the politics around climate change - in elections and other political forums, but also in the broader cultural debate - as an attempt to work out how the issue relates to some of our basic moral motives. One question in play is whether we can develop a moral vision of global ecology that will power value-based decisions by people whose identity and dignity involve doing the right thing by the planet. We know that is not just airy talk - not necessarily, anyway - because it has been a precondition of our politics around other environmental issues, such as water pollution and open-lands conservation. ${ }^{64}$ There are already signs of such a thing in states', regions', and municipalities' adopting climate-change measures. ${ }^{65}$ Seen in the light of conventional self-interest, these decisions are paradigms of futility, almost caricatures of the problems of scale that I outlined earlier - as if Salt Lake City could affect the global climate! ${ }^{66}$ Seen as part of working out moral motives whose form is partly endogenous to politics, they are both efforts to be on the right side of a global crisis and proposals about what it means to do the right thing in relation to climate change. They are intended to "scale up," not

\footnotetext{
60. See Kahan, supra note 41 , at $75-85$.

61. See id. at 73-74.

62. See id. at 75-99.

63. See Purdy, supra note 10 , at 1083-85.

64. See supra note $47-49$ and accompanying text.

65. See Engel \& Orbach, supra note 51, at 3-7 (setting out local climate initiatives).

66. For a list of cities that have (at least nominally) committed to meeting Kyoto Protocol goals locally, including Salt Lake City, see http://www.usmayors.org/climateprotection/ ClimateChange.asp (last visited February 13, 2008).
} 
just as policy models in the laboratory of democracy, but as imperatives for a responsible polity. Policies can themselves be efforts at persuasion, and these seem to fall into that category.

Second, economic activity can also be an effort at moral persuasion and training moral attitudes. For the advocates of free labor, slave societies reproduced themselves by training their members to identify with hierarchy and subordination, while free economic relations taught people to approach one another with respect and forbearance. ${ }^{67}$ By comparison, every aspect of the current economy reflects and reinforces the expectation that greenhouse gas emissions are costless, from non-dense housing and transport patterns to energy-inefficient architecture. Local climate policies and individual decisions such as buying carbon offsets are efforts to create the opposite expectation, to model an economy that would be relentlessly oriented toward taking account of the harms of emissions. Adopting national legislation that put a price on such emissions, either by tax or by cap-and-trade, would affect static judgments about the relative costs and benefits of consumption and investment decisions; but it would also dynamically affect attitudes about what is a morally appropriate economy. Such attitudes, in turn, affect the prospect of every nation passing such legislation. This, then, leads to a third point: economic and political decisions will be mutually reinforcing in the developing debate about climate change.

Finally, there is an unavoidable argument about what counts as reciprocity in climate policy. The failure of the Kyoto Protocol in the United States had importantly to do with a conception of fairness: that for the United States to take on mitigation costs while major developing-country emitters do not would make American taxpayers suckers in a non-reciprocal global scheme. ${ }^{68}$ A very different sense of fairness, however, is at work in some developing countries, such as India, where the conventional view is that because rich countries contributed most of the current anthropogenic atmospheric carbon, it would make suckers of developing countries to ask them now to take on the costs of mitigating a problem whose benefits have flowed mostly to generations of rich Europeans and Americans. ${ }^{69}$ Any global

67. See Purdy, supra note 10.

68. See Luntz, supra note 20.

69. For a discussion of this issue in international distributive terms, see SINGER, supra note 20, at 27-34. For an account of developing-country perspectives on the question, see LAVANYA RAJAMANII, DIFFERENTIAL TREATMENT IN INTERNATIONAL ENVIRONMENTAL LAW 216-36 (2006). 
climate accord will have to overcome conventional forms of collective-action problems; but it will also have to contend with this difference in ideas of what would count as a scheme of reciprocity. Success on this front will not just mediate among existing ideas of reciprocity, but revise those ideas going forward. (I do not mean, by the way, that there will have to be consensus on this issue, or that values rather than material interests will be the main drivers of an agreement, just that the terms of any possible agreement, and what will be required for successful implementation, will both depend on and affect how people in relevant countries understand fairness and reciprocity in climate change.) One challenge in the climate debate is whether it is possible to develop a shared, or at least overlapping, view of the appropriate distribution of environmental benefits and burdens among nations and across generations.

\section{CONCLUSION}

Sometimes, impossibility really is impossibility. At other times, it is potential that has not yet become real. A short list of things thought impossible by the best minds of previous centuries includes some of the axioms of present life: racial and sexual equality, orderly democracy, and economies based on individual choice and selfinterest. These were the wild-eyed utopian dreams of other times, set against widely shared assumptions about human nature and institutional limits. ${ }^{70}$ Two of those onetime utopian dreams, markets and democracy, are now sources of our own sense of limitation, our reasons for suspecting that climate change may be insurmountable. At the same time, viewed dynamically, they are among the places where we may develop new ideas about our preferences, values, and commitments, which could anchor a response to climate change.

Climate change demands as much technical expertise, and as broad a range of it, as any problem in history. Natural science, engineering, economics, the fine points of institutional design, are all front-and-center and will remain there. Nonetheless, the problem is more than technical. Technical solutions will interact with developing ideas about what is right, fair, and dignified. Success will mean moving outward the limits of the possible.

70. For early-modern arguments that democratic self-rule and market-based economic order would lead inevitably to anarchy, see Extract from the Debates at Putney, in THE ENGLISH LEVELLERS 102, 102-30 (Andrew Sharp ed., 1998). I trace the fate of some of the ideas in JEDEDIAH PURDY, A TOLERABLE ANARCHY: FREEDOM AND COMMUNITY IN AMERICAN LIFE (forthcoming 2009). 